\title{
Some Potential Problems for Measuring Ammonia EMISSIONS FROM FARM STRUCTURES
}

\author{
A. M. Lefcourt
}

\begin{abstract}
The ability to accurately measure ammonia emissions from farm buildings is an important issue both for establishing emissions regulations and for effective evaluation of mitigation techniques. Most techniques for measuring emissions rely on sub-sampling within a space. This study examines the influence of sub-sampling under a variety of conditions on estimated ammonia recoveries. Tests were made using a large environmental chamber with controlled releases of ammonia from a gas cylinder from one of two positions within the chamber. Ammonia concentrations were measured in continuous air samples from either a single exhaust duct or a sampling port in the exhaust plenum where exhaust gases were well mixed. The chamber temperature was maintained at $22.2^{\circ} \mathrm{C}$ with an airflow of 10.5 air exchanges per hour. For measurements made in the exhaust duct, ammonia recoveries were $217 \%$ when the release position and the sampling duct were aligned in terms of chamber airflow, and were 52\% when the positions were not aligned. Placing a wooden barrier between aligned release and measurement positions only reduced ammonia recoveries to $173 \%$. In contrast, using an oscillating fan to disperse the ammonia release reduced ammonia recoveries to $78 \%$. When measurements were made in the plenum, recoveries were essentially $100 \%$, and placement of a continuously wetted barrier between the release position and the exhaust ducts did not influence recoveries. It is suggested that measurement of ammonia emissions be restricted to farm structures with well-defined airflows and a limited number of exhaust openings, and that the most accurate method for estimating ammonia emission rates would be to collect and mix all of the exhaust streams from a structure prior to continuously measuring ammonia concentration and airflow.
\end{abstract}

Keywords. Ammonia volatilization, Livestock buildings, Measurement techniques.

A ccurate measurements of ammonia emissions from farm structures are critical for evaluating the effectiveness of potential mitigation techniques and for establishing fair and equitable regulations (Wathes et al., 1998). Most techniques for estimating ammonia fluxes from farm structures are based on sub-samples. For example, a common method is to measure airflow from a single opening, determine the ammonia concentration in the exhaust air from that opening, and then multiply airflow times concentration times the total number of openings (Demmers et al., 2001; Monteny et al., 1998; Phillips et al., 2000, 2001). In addition, there are a number of factors that have been hypothesized to influence emissions, including surface materials within structures, wetness of surfaces, and local perturbations of airflow (Demmers et al., 2000, 2001). The purpose of this study was to examine the influence of sub-sampling and factors hypothesized to influence measurement of emissions by measuring emissions from a large environmental chamber under a variety of controlled, potentially adverse, conditions.

Article was submitted for review in December 2002; approved for publication by the Structures \& Environment Division of ASAE in June 2002.

The author is Alan M. Lefcourt, ASAE Member Engineer, Research Biomedical Engineer, USDA-ARS, Henry A. Wallace Beltsville Agricultural Research Center, Building 303 Powder Mill Rd., Beltsville, MD 20705; phone: 301-504-8450; fax: 301-504-9466; e-mail: alefcour@anri.barc.usda.gov.

\section{MATerial ANd Methods}

Controlled quantities of ammonia were released in the chamber from a small cylinder containing anhydrous ammonia. The actual quantity of ammonia released was determined by measuring the change in cylinder weight with an accuracy of $0.02 \mathrm{~g}$. Estimated ammonia release was determined by multiplying the average increase in ammonia concentration in the exhaust air times the measured mass airflow rate times the duration of the test period. The percentage of ammonia recovered was determined by dividing the estimated quantity of ammonia released by the actual quantity of ammonia released.

\section{Chamber Specifications}

The chamber measures $7.4 \mathrm{~m}$ wide $\times 10.5 \mathrm{~m}$ long $\times 3.4 \mathrm{~m}$ high. Air temperature in the chamber did not deviate from the setpoint of $22.2^{\circ} \mathrm{C}$ by more than $0.1^{\circ} \mathrm{C}$; relative humidity was maintained at less than $60 \%$. Detailed descriptions of chamber design, operation, and control functions have been published (Lefcourt et al., 2001).

\section{Chamber Airflow}

Conditioned outside air is supplied to the chamber using a single large supply plenum that feeds six supply ducts. Each of these supply ducts connects to a single $41 \times 41 \mathrm{~cm}(16 \times$ 16 in.) ceiling diffuser. The six diffusers run longitudinally along one edge of the chamber. Air is exhausted from the chamber through six $41 \times 41 \mathrm{~cm}(16 \times 16 \mathrm{in}$.) exhaust grills above the floor on the wall opposite the diffusers. Each of the exhaust grills connects to a $41 \times 25 \mathrm{~cm}(16 \times 10 \mathrm{in}$.) vertical 


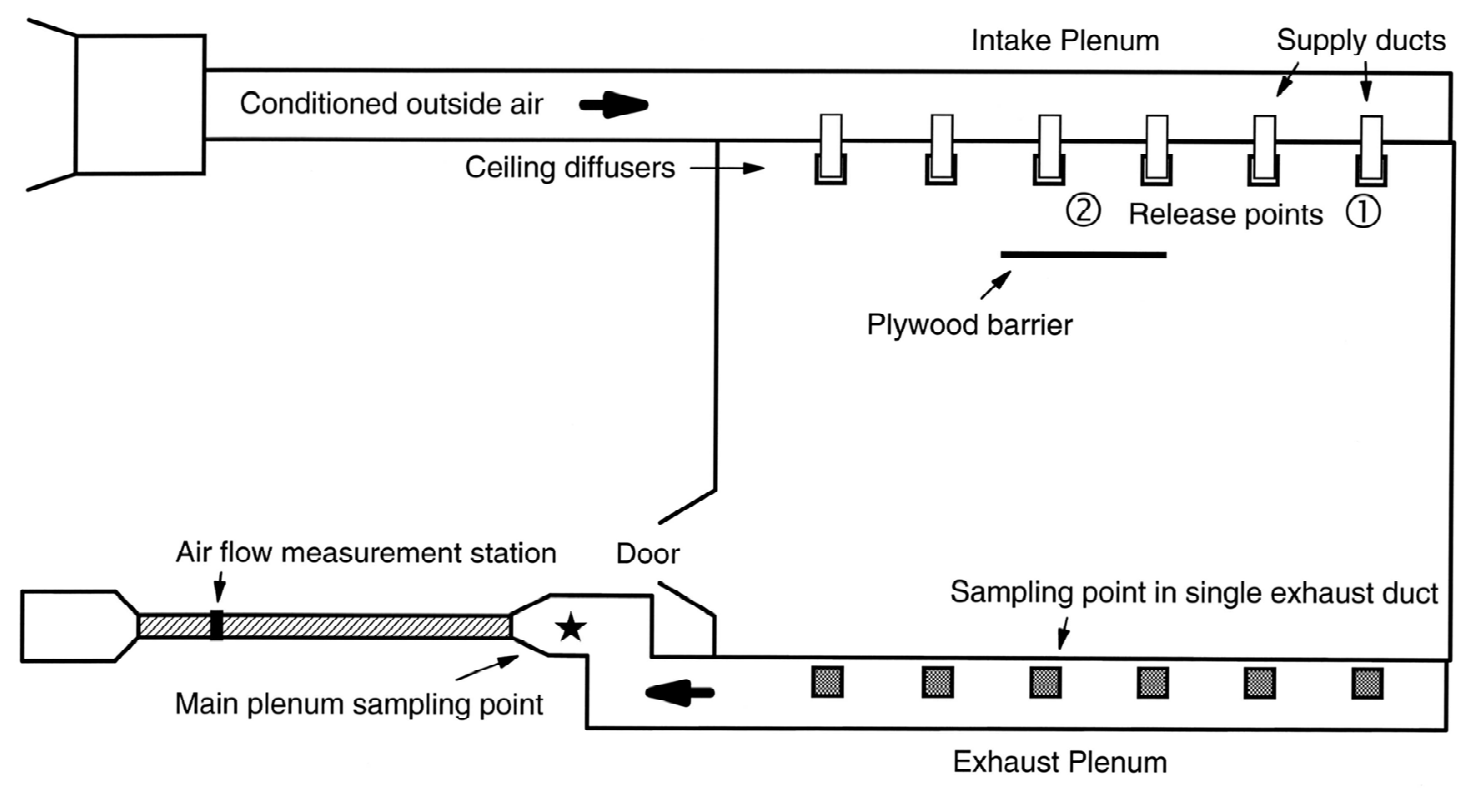

Figure 1. Top view of the environmental chamber showing the two ammonia release positions, the two air sampling points, and the location of the plywood barrier when used. The location of the fan when used is the same as release point 1 . Exhaust grills are centered $46 \mathrm{~cm}$ above the chamber floor; the shaded squares represent the cross-section of the exhaust ducts connecting these grills with the main exhaust plenum above the chamber.

duct; the six exhaust ducts feed a single large exhaust plenum above the chamber (fig. 1; Lefcourt et al., 2001).

Airflow rate in the exhaust plenum was maintained to within $1 \%$ of the setpoint of $42,475 \mathrm{~L} / \mathrm{min}$ (1500 CFM) using an airflow monitoring station, which is located in the main exhaust plenum and contains a pitot tube array, and variable-speed intake and exhaust fans (Lefcourt et al., 2001). The system controller compensates for ambient conditions by adjusting the entered setpoint for airflow rate so that the mass flow rate under the current operating conditions is equivalent to the mass flow rate of the entered setpoint under the conditions of dry air at $1 \mathrm{~atm}$ and $21.1^{\circ} \mathrm{C}$ $\left(70^{\circ} \mathrm{F}\right)$. Measurements used for these calculations include velocity pressure, air temperature, atmospheric pressure, and relative humidity.

\section{Ammonia Release and Measurement}

Ammonia was released from a $150 \mathrm{~mL}$ sampling bottle (316L-HDF4-150, Swagelock, Cleveland, Ohio) containing anhydrous ammonia. Release was controlled using a stem valve (SS-14DKS4-S4-E, Swagelock) in series with an adjustable precision metering valve (SS-SS4-EPVH, Swagelock) set at 0.4 turns open. A complete description of the release mechanism has been published (Lefcourt, 2001). Ammonia concentrations in exhaust air were measured using a Chillgard RT Model 3800 infrared gas monitor (Mine Safety Appliances Co., Pittsburgh, Pa.) housed in a controlled-temperature oven held at $35^{\circ} \mathrm{C}$. Measurements were made at $2-$ second intervals and averaged over 30 seconds (15 readings). The averaged readings were recorded to disk. As these readings oscillate with a 1 to 2 min time constant due to the inherent operating characteristics of the ammonia analyzer, ammonia readings for graphs were digitally filtered (Blackman, 64 points, 8-min time constant; Elliot, 1987). For readings averaged over $10-\mathrm{min}$ intervals, the linear correlation coefficient for standard gases of $0.0,10.0,20.9$, and $49.5 \mathrm{ppm}$ ammonia was greater than 0.99 , and the coefficients of variation of 5.0 and $10.5 \mathrm{ppm}$ gas samples constructed by mixing 10.0 and $20.9 \mathrm{ppm}$ standards equally with pure nitrogen were less than 3\% (Lefcourt, 2001).

Air for ammonia measurements was sampled using PVC tubing lined with Teflon (Tygon SE-200; $3.2 \mathrm{~mm} \mathrm{ID,} 6.4 \mathrm{~mm}$ OD) from either of two points: the center of a single exhaust duct, or the sampling port in the exhaust plenum (fig. 1). The single exhaust duct sampling point was located in the center of one of the vertical ducts, $30 \mathrm{~cm}$ above the top of the wall exhaust grill. Ammonia was released from either of two positions in the chamber. Position 1 was towards one corner of the chamber, under the supply diffusers. Position 2 was towards the center of the chamber, under the supply diffusers and opposite the exhaust duct used for ammonia measurements (fig. 1). Data from the prior chamber calibration study indicated that recoveries for ammonia released from these two positions were essentially identical when ammonia concentration was measured in air sampled from the sampling port in the exhaust plenum (Lefcourt, 2001).

\section{Ammonia Recovery Calculations}

The time sequence for individual trials was a $30-\min$ baseline period, ammonia release for $30 \mathrm{~min}$, a $30 \mathrm{~min}$ stabilization period, and a second 30-min baseline period (figs. 2 to 4 ). The total elapsed time for each trial was 120 min. The average increase in ammonia concentration due to a release was estimated by averaging measured concentrations over the combined release and stabilization periods and subtracting the average over the two baseline periods. The estimated ammonia release was calculated as: average concentration increase $(\mathrm{ppm}) \times$ duration of combined release and stabilization periods $(60 \mathrm{~min}) \times$ mass airflow rate $\times 0.7052\left(\mu \mathrm{g} \mathrm{L}^{-1} \mathrm{ppm}^{-1}\right)$. The conversion factor $0.7052 \mu \mathrm{g}$ 


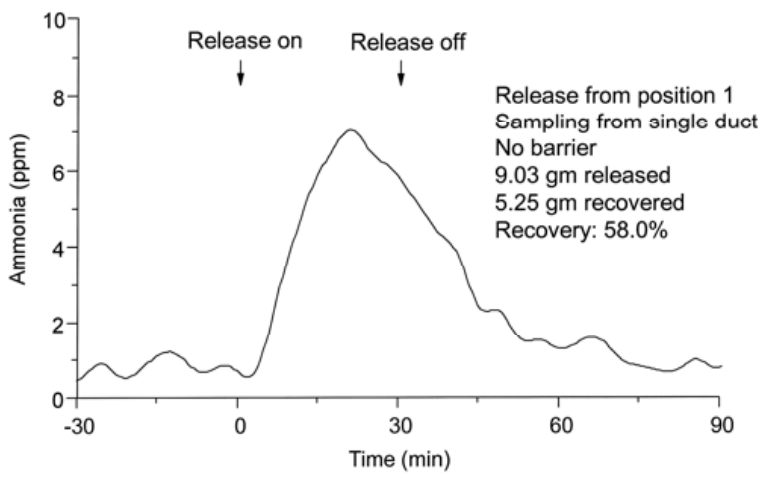

Figure 2. Example of measured ammonia concentration over time in response to release of ammonia into a large environmental chamber. In this case, the ammonia release position was in one corner of the chamber, and the air sampling point was in a single exhaust duct in the center of the opposite wall.

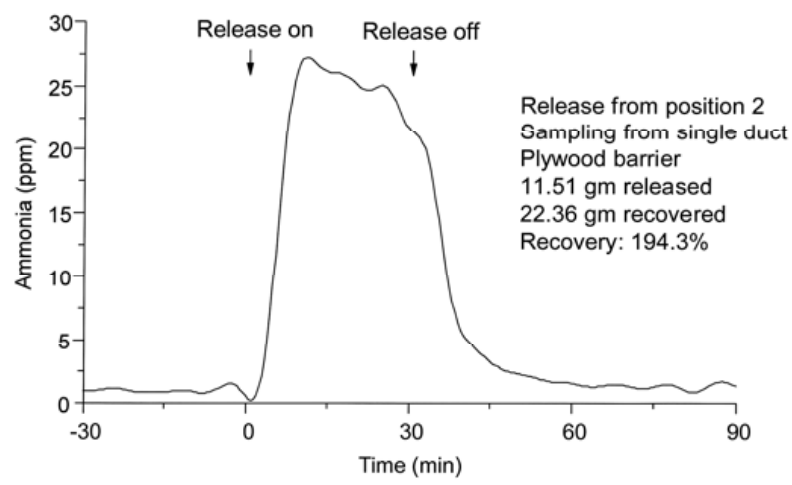

Figure 3. Example of measured ammonia concentration over time in response to release of ammonia into a large environmental chamber. In this case, the ammonia release position and the air sampling point in the single exhaust duct were aligned in terms of chamber airflow. A plywood barrier was placed between release and sampling locations.

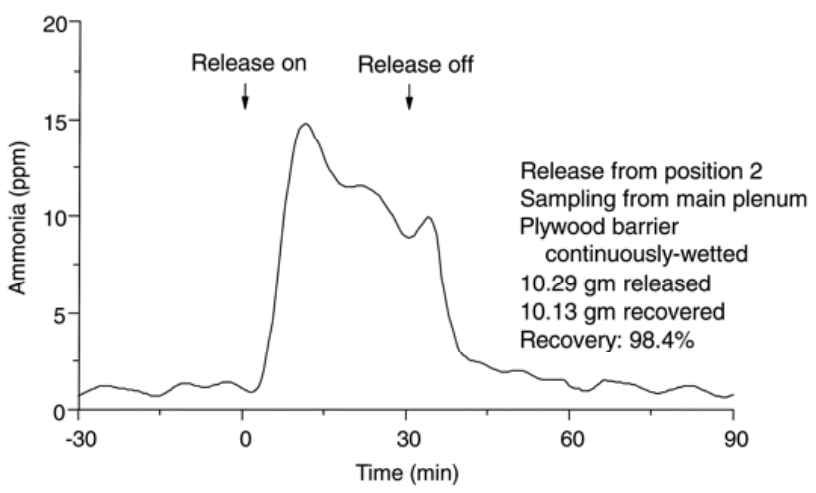

Figure 4. Example of measured ammonia concentration over time in response to release of ammonia into a large environmental chamber. In this case, the ammonia release position was along the center of the wall adjacent to the air intake ducts, and the air sampling point was in the main plenum. A continuously wetted plywood barrier was placed between the release location and the wall containing the exhaust ducts.

$\mathrm{L}^{-1} \mathrm{ppm}^{-1}$ is the result of using the ideal gas law to determine the number of molecules in $1 \mathrm{~L}$ of gas at $1 \mathrm{~atm}$ and $21.1^{\circ} \mathrm{C}$, dividing by $10^{6}$, and multiplying by the molecular weight of ammonia.
No attempt was made to determine mass airflow or ammonia mass flow through the single exhaust duct, as this information is not necessary to estimate ammonia mass flow through the chamber based on measurements made in the single exhaust duct. The ammonia mass flow rate through the chamber can be estimated by multiplying the increase in ammonia concentration in the exhaust duct times the total chamber airflow rate. The assumption is that ammonia concentrations in the exhaust duct where measurements were made are representative of concentrations in the other exhaust ducts.

\section{EXPERIMENTAL TRIALS}

For the first trial, the experimental design was a $2 \times 2$ factorial in which ammonia was released from either of the two release positions and was measured at either of the two measurement points. For the second trial, the experimental design was also $2 \times 2$ factorial in which ammonia was released from position 2 . The two factors were presence or absence of a plywood barrier $(2.44 \times 2.44 \mathrm{~m}$; fig. 1$)$ between the ammonia release position and the air sampling point in the single duct, and the location of the ammonia sampling point. For the third trial, ammonia was released from position 2 and measured in the single opposing exhaust duct under three conditions: no fan, oscillating fan, and fan at $45^{\circ}$ angle. The fan (16 inch, high speed setting, 2836 CFM; model 4C508H, Dayton Electric Manufacturing Co., Niles, Ill.) was placed at release position 1 . In the oscillating mode, the fan was set to sweep a $90^{\circ}$ arc, which essentially covered the entire chamber. Alternatively, the fan was set to continuously blow towards the far corner of the chamber. For the fourth trial, ammonia was released from position 2 and measured in the exhaust plenum under four conditions: no barrier, barrier, barrier soaked prior to ammonia release, or continuously wetted barrier. To continuously wet the barrier, a garden hose was attached across the top of the plywood barrier, one end of the hose was capped, and $2 \mathrm{~mm}$ holes were drilled every $5 \mathrm{~cm}$. In use, running water covered the entire barrier surface. Water ran from the bottom of the barrier into a recessed gutter immediately below the barrier (Lefcourt, 2001).

A number of measurement conditions were replicated across the four trials. In such cases, only one set of measurements was actually made. For example, one measurement condition common to trials 2 and 4 was ammonia release from position 2 , use of a dry barrier, and air sampling from the main plenum. Only one set of three replicate measurements was made for this measurement condition. It should be noted that the error associated with a set of measurements used in different comparisons varied based on the statistical model used for that comparison, i.e., the errors are a function of the pooled variance associated with each statistical model.

\section{Statistical Analyses}

Data were analyzed using PROC GLM (SAS, 1999). For trial 1, the model included the factor LOC (release position) by DUCT (measurement point). For trial 2, the factor was BARRIER (yes or no) by DUCT. For trials 3 and 4 , the factors were FAN (none, oscillating, or $45^{\circ}$ ) or TREAT (no barrier, barrier, wet barrier, or continuously wetted barrier). 


\section{RESULTS}

Measured ammonia concentrations increased rapidly following the onset of ammonia release, reached a peak within 9 to $16 \mathrm{~min}$, decreased slowly during the remaining release period, and then, during the stabilization period, rapidly returned to baseline within about $20 \mathrm{~min}$ of stopping the ammonia release (figs. 2 to 4 ). Peak measured ammonia concentration ranged from 5 to $27 \mathrm{ppm}$. Baseline concentrations were around $1 \mathrm{ppm}$.

\section{Trial 1: Release Position}

The interaction of release position and measurement point was significant $(\mathrm{P}<0.001)$. Recoveries for measurements made in the single exhaust duct were double or half the expected values, depending on the release position (table 1). An example of ammonia released from position 1 and sampled in the single duct is shown in figure 2 .

\section{Trial 2: EfFect of Adding a BARRIER}

The interaction of measurement point and presence or absence of a plywood barrier was significant $(\mathrm{P}<0.001)$. Recoveries for measurements made in the single exhaust duct were about double the expected values; the presence of the barrier somewhat reduced the overestimation (table 2). An example of a recovery from the single duct with the barrier in place is shown in figure 3 .

Table 1. Percentage of ammonia recovered according to position of ammonia release and measurement point. Least-square means are shown \pm SEMs.

\begin{tabular}{lcc}
\hline \multirow{2}{*}{$\begin{array}{l}\text { Position } \\
\text { of Release }\end{array}$} & \multicolumn{2}{c}{ Measurement Point } \\
\cline { 2 - 3 } Position 1 & $51.6 \% \pm 10.0 \% \mathrm{a}$ & $105.4 \% \pm 11.6 \% \mathrm{~b}$ \\
& $\mathrm{n}=4$ & $\mathrm{n}=3$ \\
\hline Position 2 & $217.2 \% \pm 10.0 \% \mathrm{c}$ & $103.6 \% \pm 11.6 \% \mathrm{~b}$ \\
& $\mathrm{n}=4$ & $\mathrm{n}=3$ \\
\hline a,b,c & Where letters differ, means tested with the Tukey-Kramer t-test were
\end{tabular}
significantly different $(\mathrm{P}<0.01)$.

Table 2. Percentage of ammonia recovered with or without the presence of a plywood barrier. Ammonia was released from position 2. Least-square means are shown \pm SEMs.

\begin{tabular}{ccc}
\hline \multirow{2}{*}{$\begin{array}{c}\text { Plywood } \\
\text { Barrier }\end{array}$} & \multicolumn{2}{c}{ Measurement Point } \\
\cline { 2 - 3 } No & $217.2 \% \pm 10.0 \% \mathrm{a}$ & $103.6 \% \pm 12.0 \% \mathrm{~b}$ \\
& $\mathrm{n}=4$ & $\mathrm{n}=3$ \\
\hline Yes & $173.4 \% \pm 12.0 \% \mathrm{c}$ & $101.3 \% \pm 12.0 \% \mathrm{~b}$ \\
& $\mathrm{n}=3$ & $\mathrm{n}=3$ \\
\hline
\end{tabular}

a,b,c Where letters differ, means tested with the Tukey-Kramer t-test were significantly different $(\mathrm{P}<0.05)$.

Table 3. Percentage of ammonia recovered according to use of a fan. Ammonia was released from position 2 and measured in the exhaust duct. Least-square means are shown \pm SEMs.

\begin{tabular}{ccc}
\hline Treatment & Recovery & $\mathrm{n}$ \\
\hline No fan & $217.2 \% \pm 10.6 \% \mathrm{a}$ & 4 \\
Oscillating fan & $77.9 \% \pm 12.2 \% \mathrm{~b}$ & 3 \\
Fan at $45^{\circ}$ & $86.4 \% \pm 12.2 \% \mathrm{~b}$ & 3 \\
\hline
\end{tabular}

a,b Where letters differ, means tested with the Tukey-Kramer t-test were significantly different $(\mathrm{P}<0.01)$.
Table 4. Percentage of ammonia recovered according to barrier status. Ammonia was released from position 2 and measured in the main plenum. Least-square means are shown \pm SEMs.

\begin{tabular}{lcc}
\hline Treatment & Recovery & $\mathrm{n}$ \\
\hline No barrier & $103.6 \% \pm 1.7 \%$ & 4 \\
Dry barrier & $101.3 \% \pm 1.7 \%$ & 3 \\
Soaked barrier & $105.1 \% \pm 1.7 \% \mathrm{a}$ & 3 \\
Continuously wetted barrier & $98.5 \% \pm 1.7 \% \mathrm{~b}$ & 3
\end{tabular}

a,b Where letters differ, means tested with the Tukey-Kramer t-test were significantly different $(\mathrm{P}<0.05)$.

\section{Trial 3: Effect of Adding a Fan To Disperse} RELEASED AMMONIA

The model for fan effects was significant $(\mathrm{P}<0.001)$. Recoveries for measurements made in the single exhaust duct were double the expected values with no fan and less than expected with either an oscillating or stationary fan (table 3).

\section{Trial 4: EFFect OF WeTted BARRIER}

The model for barrier effects was not significant $(\mathrm{P}<$ 0.11). Recoveries for all cases approached $100 \%$ (table 4 ). An example of a recovery trial with ammonia measurements from the main plenum and a continuously wetted barrier is shown in figure 4.

\section{Source of Variation in Measurements}

Repeated measurements from the single duct were highly variable, which resulted in relatively high standard errors when such data were included in a statistical model. For example, in trial 4 , where measurements were made only from the main plenum (table 4), standard errors were $1.7 \%$. In contrast, when measurements from the single exhaust duct were included in analyses, standard errors ranged from $10 \%$ to $12 \%$ (tables 1 and 2). Measurement errors associated with the single duct were mitigated when the fan was used to improve mixing (table 3 ). Calculated standard errors for raw means were $16 \%$ with no fan and $1 \%$ to $2 \%$ when the fan was used.

\section{DiscuSsion}

The measured baseline ammonia concentrations and the peak concentrations following ammonia release are representative of levels commonly found on farms (Groot Koerkamp et al., 1998) and are similar to levels observed in a prior study (Lefcourt, 2001). Recoveries calculated using air sub-sampled from the totally mixed air stream in the exhaust plenum were essentially $100 \%$, while recoveries calculated using air sub-sampled from one of the six exhaust ducts were erroneous. Note that when ammonia was released from position 1 and measured in the single duct (fig. 1), the time to reach the peak in ammonia concentration was delayed relative to when ammonia was released from position 2 (figs. 3 and 4). This delay is due presumably to the time delay associated with the diffusion of the ammonia across the normal direction of airflow. The decline in measured ammonia concentrations towards the end of release periods, when ammonia was still being released, is due to cooling of the release cylinder and the resulting reduction in the partial pressure of ammonia within the release cylinder (Lefcourt, 2001). 
Due to health and environmental concerns, there is broad interest in rates of ammonia release from farm structures and in methods to reduce these emissions (Demmers et al., 2001; Groot Koerkamp et al., 1998; Lefcourt and Meisinger, 2001; Phillips et al., 1999; Wathes et al., 1998). In this regard, there is considerable interest in developing standardized methods for estimating ammonia emission rates (Demmers et al., 2001; Monteny et al., 1998; Phillips et al., 2000, 2001; Wathes et al., 1998). Two primary questions need to be addressed for the development of reliable methodologies: first, whether it is possible to determine a reasonable emission rate estimate by sub-sampling a portion of the exhaust from a building, and second, whether conditions within a structure can be a source of bias.

In the first case, the underlying assumptions in using measurements from a portion of the exhaust air are that the total, effective, exhaust airflow can be determined and that the ammonia concentrations in the portion of air subsampled are representative of the average emission concentrations from the structure. Estimating the total exhaust airflow from buildings is difficult (Demmers et al., 2000, 2001; Monteny et al., 1998; Phillips et al., 2000). Reasonable estimates can be made for mechanically ventilated structures; however, reliable air exchange estimates for naturally ventilated structures are difficult to obtain and even more difficult to validate. Even for mechanically ventilated structures, eddies across large openings can affect measurement accuracy. In all cases, accurate measurement of airflows requires sophisticated instrumentation. In this study, airflow was controlled with great accuracy; the question addressed was: under what conditions could a representative ammonia concentration be determined using air subsampled from a portion of the total exhaust airflow?

The first trial examined the effect of location of release within the structure. When ammonia concentrations were measured in one of the six exhaust ducts, air-streaming effects led to highly variable, erroneous, recovery estimates (table 1). This result is consistent with what might be expected, considering the vagaries of airflow within farm structures (Demmers et al., 2000). To test if disrupting or mixing the ammonia stream released from the cylinder might mitigate errors due to sub-sampling in the duct, a large plywood barrier was placed between the points of ammonia release and measurement, or a fan was used to redirect and mix the ammonia stream released from the cylinder. The barrier somewhat reduced the overestimation of ammonia recoveries; however, estimated recoveries were still variable and erroneous (table 2). The use of the fan eliminated problems with variability of recovery estimates; however, the estimates were less than $100 \%$.

In general, sub-sampling from a portion of the chamber exhaust resulted in erroneous recovery estimates. Only with the use of the fan was the variability in recovery estimates reduced to the level seen when ammonia concentrations were measured in air sampled from the exhaust plenum. These results suggest that it might be possible to get accurate and precise measurements of ammonia emissions from structures if fans are used to create sufficient turbulence within the structure to allow thorough mixing before the exhaust air is sub-sampled. The drawback of this approach is that the increased air movement will increase the rate of ammonia volatilization within the structure (Andersson, 1995; Monteny et al., 1998).
Additional factors that could influence ammonia release measurements include the material composition of the structure and whether surfaces within the structure are wet. Wood is a porous material commonly used in structures. In this study, placing a large plywood barrier downstream from the point of ammonia release did not alter recoveries when ammonia concentrations were measured in the main plenum (table 4). In addition, continuously wetting the barrier had no impact on calculated recoveries. These results suggest that the material composition of structures and the degree of wetness of surfaces are not important factors to consider when estimating ammonia release rates from structures.

To date, the most highly sanctioned method for measuring air exchange rates in naturally ventilated buildings is the use of tracer gases (Demmers et al., 2001; Phillips et al., 2001). Although this study was designed principally to test effects of air streaming on the ability to measure representative ammonia concentrations in exhaust air, the data can also be used to address the question of the reliability of using tracer gases to estimate air exchange rates. In terms of estimating the air exchange rate, the ammonia release can be considered to be the release of a trace gas. Given that the actual chamber airflow varied by less than $1 \%$, the error in recovery estimates can be interpreted as equivalent errors in measuring airflow. Thus, airflow estimates are $50 \%$ to $200 \%$ of actual airflows. This interpretation of the ammonia recovery data illustrates the potential danger of using tracer gas methods for estimating air exchange rates.

\section{Practical Considerations}

Estimating ammonia emission rates is a multifaceted process with many potential pitfalls. A common pitfall is to disregard the fact that, when estimating emission rates, the effects of errors in estimating the volumetric air exchange rate and the average difference in concentration of the substance of interest in supply and exhaust air are multiplicative rather than additive. An example of a worst-case scenario based on the results of this study would be to release a trace gas from position 1 , to have a "hot spot" of ammonia release from position 2 , and to measure both the trace gas and ammonia in the single duct. In this case, the "measured" airflow would be almost double the actual airflow (the $51.6 \%$ recovery from table 1 translates to a $94 \%$ error), and the measured ammonia concentration would be more than double the actual average concentration (the $217 \%$ recovery from table 1 translates to a $117 \%$ error); the total error would be $421 \%(1.94 \times 2.17)$ and not $211 \%(0.94+1.17)$. This simple example illustrates the effect of muliplicative errors and demonstrates how easy it would be to overestimate ammonia emissions by over four times using a common experimental design.

It can be argued that the use of a point source as opposed to a diffuse source to examine potential errors is unrealistic, as there is seldom a single source of ammonia release within a farm structure. However, the conceptual basis for using a diffuse source is the assumption that errors due to local effects will average out. In reality, there are often hot spots of ammonia release within a structure. Examples might be the opening to a manure pit in one area of the barn, or the preference of animals to urinate in a corner of the barn. Using a diffuse source for testing would negate the ability to determine the impact of such hot spots on factors affecting estimates of ammonia emissions. In actual practice, a diffuse 
trace source would, in most cases, result in more accurate estimation of the ventilation rate. However, in this study, the ventilation rate was known with great accuracy, and potential errors for estimating emissions rates still ranged from $50 \%$ to $200 \%$. This finding illustrates that it can be a gamble to assume that measurements made at a single point are representative of the average ammonia concentration in the exhaust air. One solution would be to measure ventilation rate and ammonia concentration at all exhaust openings. An alternative would be to verify the assumption that measurements made at a subset of the exhaust openings can be used to reliably estimate total emissions.

Another potential source of error that is often overlooked is the effect of poor estimation of ammonia concentrations in supply air. Emission rates are a function of differences in concentration between supply and exhaust air. For a more detailed discussion of this issue, see Lefcourt (2001).

Estimation of emission rates can also be problematic when ventilation rates change over time and ammonia concentrations are measures using averaging or integrating methods. Consider the case in which a ventilation fan cycles between a low and a high speed, which results in ventilation rates of $4000 \mathrm{~L} / \mathrm{min}$ and 40,000 L/min, respectively. For any given emission rate, the emission rate is the differential ammonia concentration in the exhaust air times the ventilation rate. If the ammonia concentration in the supply air is assumed to be zero, then the ammonia concentration in the exhaust air is inversely proportional to the ventilation rate. However, increased airflow generally causes an increase in emission rate (Andersson, 1995). The exact increase in emission rate is hard to predict because it is a function of factors such as the actual airflow rate across the surface of the emitting substance, the surface roughness of the substance, and crust formation, as well as the physical and chemical properties that drive the emissions process.

For this example, a reasonable assumption would be that the ammonia emissions rate at the high airflow rate is double the emission rate at the low airflow rate. Consider the case in which ammonia concentration is measured over a 2-hour time period; during half of the time the airflow is $4000 \mathrm{~L} / \mathrm{min}$ and ammonia concentration is $60 \mu \mathrm{g} / \mathrm{L}$, and during the other half of the time the airflow is $40,000 \mathrm{~L} / \mathrm{min}$ and the ammonia concentration is $12 \mu \mathrm{g} / \mathrm{L}$. Under these circumstances, the actual amounts of ammonia emitted for the cumulative hour of low and high airflow would be 14.4 and $28.8 \mathrm{gm}$, respectively, for a total of $43.2 \mathrm{gm}$. The average airflow would be $22,000 \mathrm{~L} / \mathrm{min}$, and the average ammonia concentration would be $36 \mu \mathrm{g} / \mathrm{L}$. Using these averages, the estimated amount of ammonia emitted over the 2-hour period would be $95.0 \mathrm{gm}$.

Thus, in this example, averaging resulted in an overestimation error of the quantity of ammonia emitted of just over $200 \%$. This is only an illustrative example, and actual errors may be significantly less depending on the magnitude of the changes in airflow rates and actual effects of airflow rates on emission rates. A specific solution for the example problem would be to use two separate averaging measurement systems, with one engaged during periods of low airflow and the second during periods of high airflow. However, if airflow continuously varies over a significant range, then the only real solutions are to measure airflow rate and ammonia concentrations continuously, or to use a measurement device that integrates ammonia mass flow over time, independent of airflow rate.

Based on the results of this study and the illustrative examples above, it is clear that the ease, cost, accuracy, and reliability of making ammonia emission measurements from farm structures can be drastically improved when studies are restricted to buildings with well-defined airflows and a limited number of exhaust openings. Tradeoffs among the costs for monitoring equipment, accuracy of measurements, and reliability suggest that a reasonable alternative would be to collect and mix all of the exhaust streams from a structure with a limited number of exhaust openings prior to continuously measuring ammonia concentration and airflow. One inexpensive method for mixing the exhaust streams would be to construct an external duct system with framing and plastic sheeting.

\section{Summary AND CONClusions}

Results from this study indicate that significant errors in estimating ammonia emission rates from farm structures can occur if air leaving the structure is not totally mixed prior to sampling. When only a portion of the air leaving the chamber was sub-sampled, estimated release rates were $50 \%$ to $200 \%$ of actual values, depending on the relative locations of the ammonia origination and measurement. Attempts to mitigate air-streaming effects by placing a barrier between points of ammonia release and sampling, or by using a fan to disperse released ammonia, were only partially successful. In contrast, recoveries calculated using totally mixed air samples were essentially $100 \%$, even when a continuously wetted barrier was placed adjacent to the point of ammonia release. It is suggested that measurement of ammonia emissions be restricted to farm structures with well-defined airflows and a limited number of exhaust openings, and that the most accurate method for estimating ammonia emission rates would be to collect and mix all of the exhaust streams prior to continuously measuring ammonia concentration and airflow.

\section{REFERENCES}

Andersson, M. 1995. Ammonia volatilization from cow and pig manure: Results of laboratory studies with a new climate chamber technique. Report No. 98. Lund, Sweden: Swedish University of Agricultural Sciences, Department of Agricultural Biosystems and Technology.

Demmers, T. G .M., L. R. Burgess, V. R. Philips, J. A. Clark, and C. M. Wathes. 2000. Assessment of techniques for measuring the ventilation rate, using an experimental building section. J. Agric. Eng. Res. 76(1): 71-81.

Demmers, T. G. M., V. R. Philips, L. S. Short, L. R. Burgess, R. P. Hoxey, and C. M. Wathes. 2001. Validation of ventilation rate measurement methods and ammonia emission from naturally ventilated dairy and beef buildings in the United Kingdom. $J$. Agric. Eng. Res. 79(1): 107-116.

Elliott, D. E., ed. 1987. Handbook of Digital Signal Processing. New York, N.Y.: Academic Press.

Groot Koerkamp, P. W. G., J. H. M. Metz, G. H. Uenk, V. R. Phillips, M. R. Holden, R. W. Sneath, J. L. Short, R. P. White, J. Hartung, J. Schröder, K. H. Linkert, S. Pedersen, H. Takai, J. O. Johnsen, and C. M. Wathes. 1998. Concentrations and emissions 
of ammonia in livestock buildings in northern Europe. J. Agric. Eng. Res. 70(1): 79-95.

Lefcourt, A. M. 2001. Large environmental chamber: Ammonia recovery calibration. Applied Eng. in Agric. 17(5): 83-689.

Lefcourt, A. M., and J. J. Meisinger. 2001. Effect of adding alum or zeolite to dairy slurry on ammonia volatilization and chemical composition. J. Dairy Sci. 84(8): 1814-1821.

Lefcourt, A. M., B. Buell, and U. Tasch. 2001. Large environmental chamber: Design and operating characteristics. Applied Eng. in Agric. 17(5): 691-701.

Monteny, G. J., D. D. Schulte, A. Elzing, and E. J. J. Lamaker. 1998. A conceptual mechanistic model for the ammonia emissions from free-stall cubicle dairy houses. Trans. ASAE 41(1): 193-201.

Phillips, V. R., D. A. Cowell, R. W. Sneath, T. R. Cumby, A. G. Williams, T. G. M. Demmers, D. L. Sandars. 1999. An assessment of ways to abate ammonia emissions from U.K. livestock buildings and waste stores: 1 . Ranking exercise. Bioresource Technology 70(2): 143-155.
Phillips, V. R., R. Scholtens, D. S. Lee, J. A. Garland, and R. W. Sneath. 2000. A review of methods for measuring emission rates of ammonia from livestock buildings and slurry or manure stores: Part 1. Assessment of basic approaches. J. Agric. Eng. Res. 77(4): 355-364.

Phillips, V. R., R. Scholtens, J. A. Garland, D. S. Lee, and R. W. Sneath. 2001. A review of methods for measuring emission rates of ammonia from livestock buildings and slurry or manure stores: Part 2. Monitoring flux rates, concentrations, and airflow rates. J. Agric. Eng. Res. 78(1): 1-14.

SAS. 1999. SAS Online Doc. Version 8. Cary, N.C.: SAS Institute, Inc.

Wathes, C. M., V. R. Phillips, M. R. Holden, R. W. Sneath, J. L. Short, R. P. White, J. Hartung, J. Seedorf, M. Schröder, K. H. Linkert, S. Pedersen, H. Takai, J. O. Johnsen, P. W. G. Grot Koerkamp, G. H. Uenk, J. H. M. Metz, T. Hinz, V. Caspary, and S. Linke. 1998. Emissions of aerial pollutants in livestock buildings in northern Europe: Overview of a multinational project. J. Agric. Eng. Res. 70(1): 3-9. 